\title{
THE SYSTEM BANDPASS REQUIRED TO AVOID DISTORTION OF EARLY COMPONENTS WHEN AVERAGING SOMATOSENSORY EVOKED POTENTIALS ${ }^{1}$
}

\author{
J. E. Desmedt, E. Brunko, J. Debecker and J. Carmeliet ${ }^{2}$ \\ Brain Research Unit, University of Brussels, 115 Bd. de Waterloo, B 1000 Brussels (Belgium)
}

(Accepted for publication: April 9, 1974)

One line of current progress in evoked potential research is concerned with the analysis of the early components of the average response recorded from the human scalp. For the somatosensory potentials evoked by finger stimulation, this trend has resulted in consistent identification of the early surface-negative cortical component $\mathrm{N}_{1}$, not only in newborn (Desmedt and Manil 1970) but also in adult man (Goff et al. 1969; Desmedt 1971: Cracco 1972). Precise estimation of $\mathrm{N}_{1}$ wave form and latency is important in studies of maturation (Desmedt et al. 1973) and of clinical disorders of the somatosensory pathway (Desmedt and Noël 1973). It is not generally appreciated that such studies require the use of a wide enough bandpass for the recording system from input amplifier to averager, including the magnetic tape recorder when this is used. Several authors using EEG amplifiers with a $3 \mathrm{~dB}$ loss at $70 \mathrm{c} / \mathrm{sec}$ (and sometimes with a special filter to reduce $50-60 \mathrm{c} / \mathrm{sec}$ mains interference) have claimed an accuracy of a fraction of a millisecond in their estimations of $\mathrm{N}_{1}$ latency, which we think is an unrealistic description of what they are actually doing. The present note calls attention to a few pertinent points.

\section{METHODS}

Our current procedure, applied since 1967 to large numbers of human subjects, uses a system bandpass from 0.016 $\mathrm{c} / \mathrm{sec}$ to $5 \mathrm{kc} / \mathrm{sec}$. It includes a FabriTek averager model 1062 or 1074 which is operated with $50-100 \mu$ sec bin width for early component analysis and, when necessary, an Ampex FR-1300 magnetic tape recorder operated at 15 inches per second (i.p.s.) (bandwidth DC to $5 \mathrm{kc} / \mathrm{sec}$ ). Low frequency fidelity is important for studies of cerebral DC shifts associated with cognition and expectancy (see Donchin and Lindsley 1969; MeCallum and Knott 1973). On the other hand, when investigating early components only, the high pass filter can be set at $0.16 \mathrm{c} / \mathrm{sec}$ but the low pass filter

${ }^{1}$ This research has been supported by grants from the Fonds de la Recherche Scientifique Medicale.

${ }^{2}$ From the Laboratoire de Métrologie nucléaire, University of Brussels. becomes rather critical, as shown in this paper. Eight normal male subjects ranging in age from 21 to 37 years were used (see details in Desmedt et al. 1973). No medication was used and the subjects remained alert but relaxed during the run, with a minimum of blinks and muscle interference. Electrical pulses of $0.2 \mathrm{msec}$ duration and $10-20 \mathrm{~mA}$ intensity were delivered every $2 \mathrm{sec}$ through silver ring electrodes to fingers II and III. The skin temperature of the hand and arm was kept at $34-36^{\circ} \mathrm{C}$ to assure a fairly normal temperature around the nerve. The contralateral cerebral response was picked up by thin subcutaneous steel needles, one over the parietal focus about $7.5 \mathrm{~cm}$ from the midline and the other on midupper forehead or ipsilateral earlobe as reference.

A number of homemade filter circuits could be inserted between the amplifier output and the averager in order to lower the upper cutoff frequency (defined as $3 \mathrm{~dB}$ loss for peak voltage of sinusoidal signals) to $3 \mathrm{kc} / \mathrm{sec}, 1 \mathrm{kc} / \mathrm{sec}$, $600 \mathrm{c} / \mathrm{sec}, 300 \mathrm{c} / \mathrm{sec}, 200 \mathrm{c} / \mathrm{sec}, 100 \mathrm{c} / \mathrm{sec}$ or $50 \mathrm{c} / \mathrm{sec}$. Two types of filters were available for each cutoff frequency, namely a simple passive $\mathrm{RC}$ network giving an attenuation of $6 \mathrm{~dB}$ per octave or an active Butterworth filter of 4 th order providing a very flat response up to cutoff and a $24 \mathrm{~dB}$ per octave roll off. Fig. 1, $A$ presents the frequency response of the entire system and its modification by inserting $100 \mathrm{c} / \mathrm{sec}$ low pass filters of either type. The input and the output of each filter circuit included a type 741 operational amplifier of gain I connected to provide a high input impedance and a low output impedance. This prevented any load on the filter cell from distorting the transfer function.

\section{RESULTS}

The general procedure of the experiments was as follows. With the 4-channel FabriTek model 1074 (4096 words) computer operated at $80 \mu \mathrm{sec}$ bin width, the evoked potential was averaged on line with 4 chosen filter conditions. The same EEG samples were simultaneously recorded with the full band width (Fig. 1, A) on magnetic tape at 15 i.p.s. They were subsequently averaged with other filter conditions to obtain a complete set of records with the 14 filters (7 cutoff frequencies with either 6 or $24 \mathrm{~dB}$ /octave attenuation). 


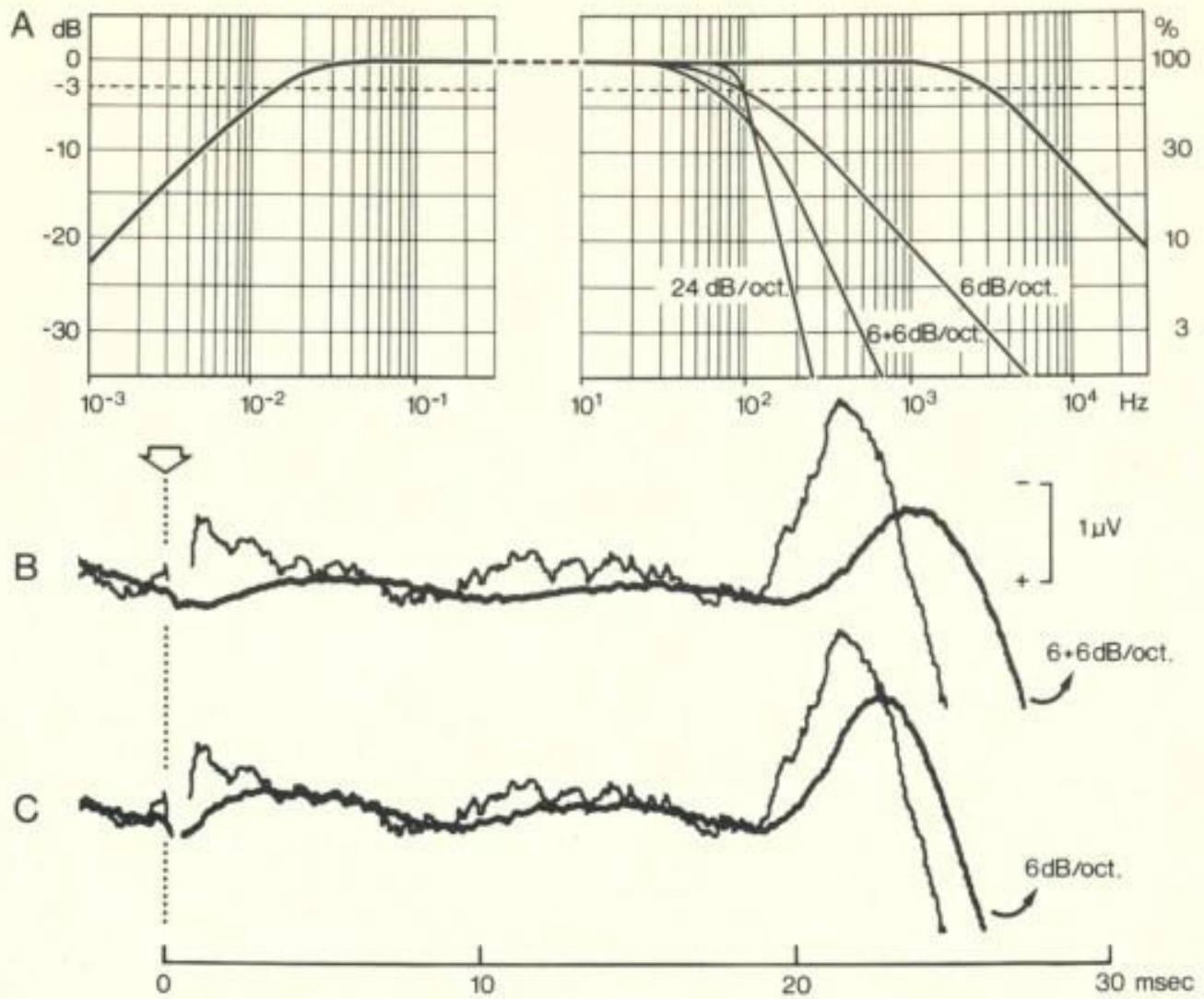

Fig. 1. A: System bandpass tested with sinusoidal signals. Abscissac, frequency, Ordinates, signal attenuation in dB (left) and in percent (right). The dotted horizontal line corresponds to an attenuation of $-3 \mathrm{~dB}$ or $-30 \%$. The thicker line corresponds to the frequency response of amplifier system with no additional filter. The 3 other curves represent the changes resulting from the insertion of 1 or 2 filter circuits of $100 \mathrm{c} / \mathrm{sec}$ with either 6 or $24 \mathrm{~dB} /$ octave roll off. The curves for the other filter circuits are similar but shifted along the abscissae. B, C : Somatosensory cerebral potentials evoked by stimulation of fingers II and III with $18 \mathrm{~mA}$ (arrow). Averages of 1024 responses, $80 \mu \mathrm{sec}$ bin width. The tracing with thinner lines was averaged with the 3 $\mathrm{kc} / \mathrm{sec}$ filter. The superimposed thicker lines correspond to the same EEG data averaged with $1(C)$ or $2(B) 100 \mathrm{c} / \mathrm{sec} 6 \mathrm{~dB} / \mathrm{oc}-$ tave filters.

Each averaging run included the same EEG data and 1024 stimuli. The input filter on the FabriTek was set at $20 \mu \mathrm{sec}$ time constant, which is short enough not to interfere with the added filters. The magnetic recording and playback did not affect the wave forms. The latter were also found to be identical when using a $10 \mathrm{kc} / \mathrm{sec}$ or a $3 \mathrm{kc} / \mathrm{sec}$ low pass filter of 6 or $24 \mathrm{~dB} /$ octave roll off. Marked distortions were observed when using filters with lower cutoff frequencies.

Fig. 1, $B$ shows the distortion of the early components of the evoked potential averaged with two cascaded $6 \mathrm{~dB}$. octave $100 \mathrm{c} / \mathrm{sec}$ filters, which changed the system bandpass as shown in A. Fig. 1,C shows the effect of a single $100 \mathrm{c} / \mathrm{sec}$ filter. Besides smoothing the trace the filters delay the peak of the negative $\mathrm{N}_{1}$ component, reduce its voltage and lead to an overestimation of the $\mathrm{N}_{1}$ onset latency.

Fig. 2 shows $80 \mathrm{msec}$ sweeps with the low pass filters set at $3 \mathrm{kc} / \mathrm{sec}$ or $100 \mathrm{c} / \mathrm{sec}$ and either $24 \mathrm{~dB} /$ octave $(A)$ or $6 \mathrm{~dB} /$ octave $(B)$ roll off. The distortion is considerably more severe with the $100 \mathrm{c} / \mathrm{sec} 24 \mathrm{~dB} /$ octave filter, which drastical- ly excludes frequencies above $200 \mathrm{c} / \mathrm{sec}$. For example, the voltage of a $300 \mathrm{c} / \mathrm{sec}$ sine wave is reduced to $1 \%$ only by this filter whereas the corresponding figure is about $30 \%$ for the $6 \mathrm{~dB} /$ octave $100 \mathrm{c} / \mathrm{sec}$ filter (Fig, 1, A).

The diagrams of Fig. 3 present pooled data on the voltage and the onset latency changes of the $\mathrm{N}_{1}$ component for the 14 filter conditions. The mean voltage of $\mathrm{N}_{1}$ in the 8 experiments was $1.3 \pm 0.9 \mu \mathrm{V}$ (s.d.) for the $3 \mathrm{kc} / \mathrm{sec}$ filter and it decreased quite markedly for the lower cutoff filters $(A, B)$. The mean onset latency of $\mathrm{N}_{1}$ for finger stimulation of $18.9 \pm 0.9$ msec in this series agreed with recent data (Cracco 1972: Desmedt and Noêl 1973) but was slightly shorter than other earlier results; it increased consistently with low pass filtering and suffered an increment of about $1.5 \mathrm{msec}$ with $6 \mathrm{~dB} /$ octave $50 \mathrm{c} / \mathrm{sec}$ and $4.5 \mathrm{msec}$ with $24 \mathrm{~dB} /$ octave $50 \mathrm{c} / \mathrm{sec}$ filters. The mean peak latencies at $3 \mathrm{kc} / \mathrm{sec}$ were $21.9 \pm 0.7$ msec for $\mathrm{N}_{1}, 27.1 \pm 1.8 \mathrm{msec}$ for $\mathrm{P}_{1}$ and $41.4 \pm 3.9 \mathrm{msec}$ for the second part of the surface-positive component, which was called no. 3 in our nomenclature (Desmedt $e t$ al. 1973). 


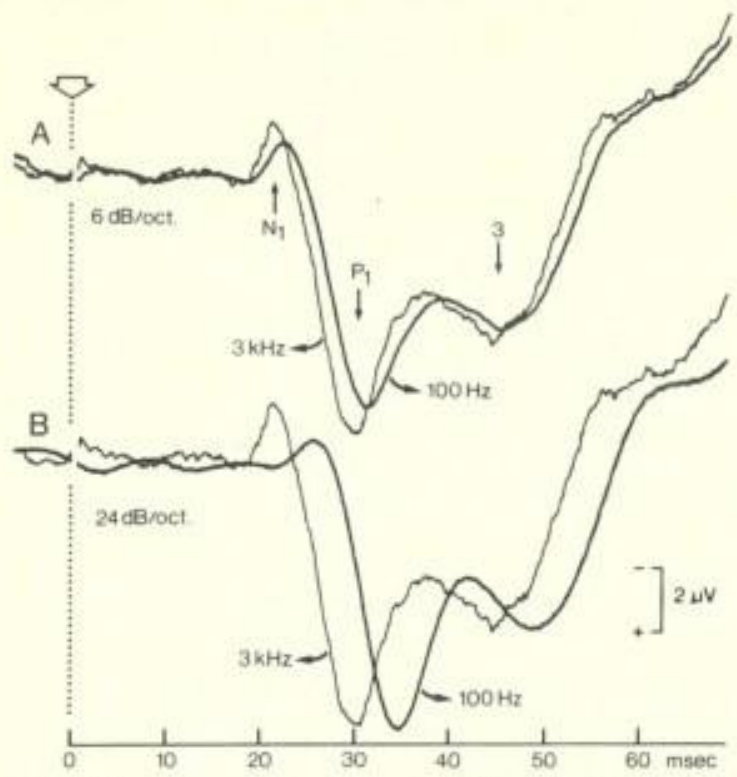

Fig. 2. Somatosensory cerebral potentials evoked by stimulation of fingers II and III with $18 \mathrm{~mA}$ (arrow). Averages of 1024 responses, $80 \mu \mathrm{sec}$ bin width. Filters of $6 \mathrm{~dB} /$ octave $(A)$ or $24 \mathrm{~dB} /$ octave $(B)$ with $-3 \mathrm{~dB}$ cutoff at $3 \mathrm{kc} / \mathrm{sec}$ (thinner tracing) or $100 \mathrm{c} / \mathrm{sec}$. The nomenclature of response components is indicated in $A$.

The mean voltage of $\mathrm{P}_{\mathrm{t}}$ was $4.4 \pm 2.8 \mu \mathrm{V}$. All peak latencies were markedly delayed by increasing filtering while the voltage of the positive components was less distorted than that of $\mathrm{N}_{1}$ (Fig. 2).

\section{DISCUSSION}

Most cerebral evoked potential studies of the last decade have been concerned with rather slow or even DC components and amplifiers of the type used in EEG machines with high cutoff at 50 or $70 \mathrm{c} / \mathrm{sec}$ are still widely used. A glance through a number of issues of this Journal indeed suggests that authors tend to prefer smoothed traces in which the high frequency noise residues have been ironed out by rather drastic filtering. However, recent investigations indicate that the early cortical components of the somatosensory potential cannot be consistently studied with a high cutoff at 50 or $70 \mathrm{c} / \mathrm{sec}$. When discussing system bandpass one must not only consider the voltage attenuation and the phase distortion of the cerebral potentials introduced by the filters of the amplifier chain, but also the analog-digital sampling rate and the input filters of the averaging computer. When using FM magnetic tape storage of the data, the characteristics of the corresponding electronics and the tape speed are also relevant. All these features must be consistent to achieve an adequate system bandpass and the latter should be made explicit in the published papers. Authors are sometimes unaware of the presence in their equipment of several filters in series, which increase the low pass roll off and exclude more sharply response components of higher frequency (Fig. I

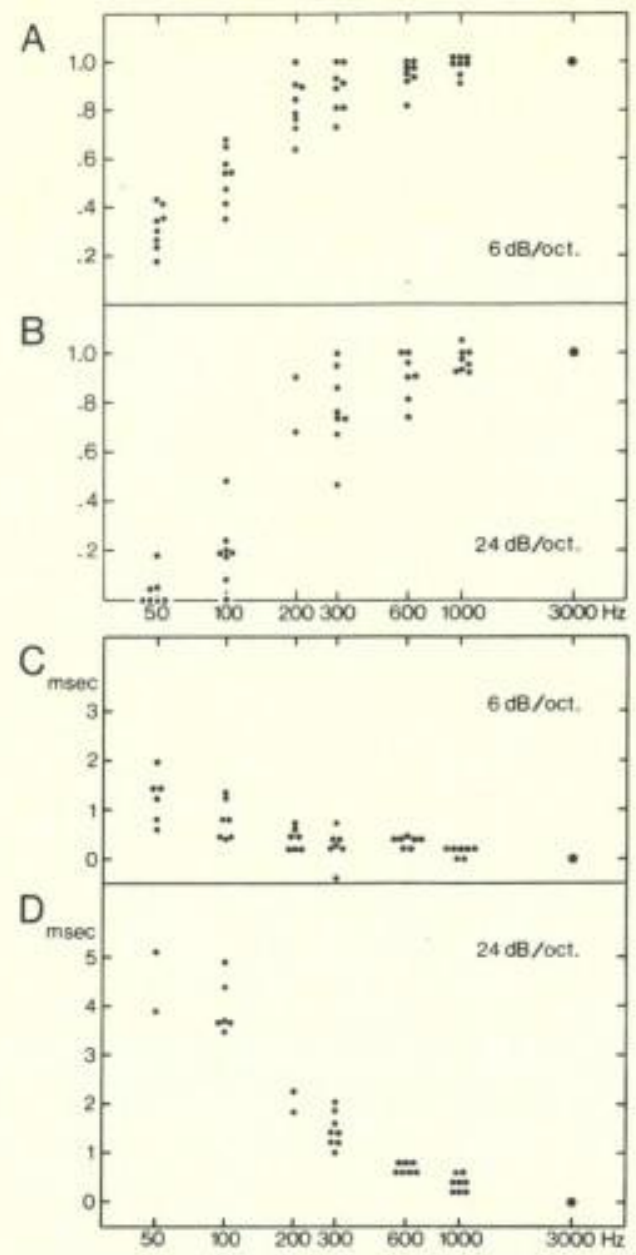

Fig. 3. Pooled data of the relative changes of $\mathrm{N}_{1}$ voltage $(A, B)$ and of the increments of $\mathrm{N}_{1}$ onset latency $(C, D)$ for various filters, the cutoff frequencies of which are indicated in the abscissae. The values for $3 \mathrm{kc} / \mathrm{sec}$ filter are taken as reference (thicker dots). Filters with either $6 \mathrm{~dB} /$ octave $(A, C)$ or $24 \mathrm{~dB}$ /octave $(B, D)$ are compared.

and 2). Such cumulative filter effects can casily be overlooked, for example when the bioelectric potentials are submitted to a first filtering process when recorded onto magnetic tape and then to a second filtering when played back from tape to averager. The records of Fig. I, B and $C$ show that the distortion of the $\mathrm{N}_{1}$ component by one $6 \mathrm{~dB}$ /octave $100 \mathrm{c} / \mathrm{sec}$ filter is indeed considerably increased when a second such filter is inserted in series.

The distortion introduced by low pass filtering is quite severe. The voltage of the early $\mathrm{N}_{1}$ component of the somatosensory potentials evoked by finger stimulation can be so reduced (Fig. 2 and $3, A$ and $B$ ) that $\mathrm{N}_{1}$ could easily be missed in sub-optimal experimental conditions (contamination by noise, impossibility to average a large number of samples, inadequate position of recording electrodes, etc.) or in patients with even mild somatosensory disorders (cf. Des- 
medt and Noc̈l 1973). The voltage of the slower components is less affected. The elimination of high frequency components and the phase shift make it increasingly difficult to identify the true onset latency of $\mathrm{N}_{1}$ which is then unduly overestimated (Fig. 3, $C$ and $D$ ). This may be of minor concern in studies of the late components but it is unacceptable in any estimation of the latency of the evoked potential and of the conduction time in the central lemniscal pathway ( $c$. Desmedt 1971; Desmedt et al. 1973). Onset latency measurements with an accuracy of $0.5 \mathrm{msec}$ or better can only be claimed if the overall bandpass extends to $3 \mathrm{kc} / \mathrm{sec}$, if the averager bin width is $100 \mu \mathrm{sec}$ or less and if 3 separate runs are compared to help differentiate the consistent onset of the wave form from residual noise. The study with the 24 $\mathrm{dB}$ /octave filters made explicit the cumulative effects of serial filtering and also showed that $\mathrm{N}_{1}$ includes significant response components in the frequency range of $100-1000 \mathrm{c} / \mathrm{sec}$. The distortion of the surface positive components by excessive filtering also leads to overestimations of their peak latencies (Fig. 2).

\section{SUMMARY}

The effects of 14 filter conditions with cutoff ranging from $3 \mathrm{kc} / \mathrm{sec}$ to $50 \mathrm{c} / \mathrm{sec}$ and with either 6 or $24 \mathrm{~dB} /$ octave roll off were studied when averaging the somatosensory cerebral potentials evoked by electrical stimulation of fingers in normal adult men. Severe distortions of latencies and voltages were observed for low pass filtering below $1 \mathrm{kc} / \mathrm{sec}$. It is emphasized that the overall system bandpass should extend to $3 \mathrm{kc} / \mathrm{sec}$ when studying the early components and when estimating the onset latency of the surface negative $\mathrm{N}_{t}$ component. Precise information about the system bandpass used should be included in published reports.

\section{RESUME}

BANDE PASSANTE REQUISE POUR EVITER LES DISTORTIONS DES COMPOSANTES PRECOCES DANS L'ANALYSE DU POTENTIEL EVOQUE SOMESTHESIQUE PAR DISPOSITIF MOYENNEUR

Les modifications des potentiels cérébraux somesthésiques évoqués par stimulation électrique des doigts chez lo sujet adulte normal subissent des modifications importantes dans leur voltage et leur latence lorsqu'on limite la bande passante en-dessous de $1 \mathrm{kc} / \mathrm{sec}$. Quatorze filtres à fréquences de coupure étagées de $3 \mathrm{kc} / \mathrm{sec}$ à $50 \mathrm{c} / \mathrm{sec}$ et avec des atténuations de 6 ou de $24 \mathrm{~dB}$ par octave ont été comparés. La bande passante doit s'étendre jusqu'à $3 \mathrm{kc} / \mathrm{sec}$ lorsqu'on analyse les composantes précoces et notamment la latence du début de la composante négative $\mathrm{N}_{1}$. Les publications devraient inclure des informations précises sur la bande passante du système utilisé.

\section{REFERENCES}

Cracco, R. Q. Travelling waves of the human scalp-recorded somatosensory evoked response: effects of differences in recording technique and sleep on somatosensory and somatomotor responses. Electroenceph, clin. Neurophysiol., 1972, 33: 557-566.

DesmfdT, J. E. Somatosensory cerebral evoked potentials in man. In A. REMOND (Ed.), Handbook of EEG and Clinical Neurophysiology. Elsevier, Amsterdam, 1971, 9 . 55-82.

Desmmit, J. E. and MANIL, J. Somatosensory evoked potentials of the normal human neonate in REM sleep, in slow wave sleep and in waking. Electroenceph. clin. Neurophysiol, 1970, 29: 113-126.

Desmpot, J. E. and Nö̈L, P. Average cerebral evoked potentials in the evaluation of lesions of the sensory nerves and of the central somatosensory pathway. In J. E. DismeDT (Ed.). New developments in electromyography and clinical neurophysiology. Karger, Basel, 1973, Vol, 2: 352-371.

Desmedt, J. E., Noêl, P., Drbecker, J. and Nameche, J. Maturation of afferent conduction velocity as studied by sensory nerve potentials and by cerebral evoked potentials. In J. E. DEsmpDT (Ed.), New detelopments in electromyography and clinical neurophysiology. Karger, Basel, 1973, Vol. 2: 52-63.

Donchin, E. and Lindsir, D. B. (Eds.), Average evoked potentials: methods, results and enaluations. NASA SP. 191, Washington, D.C., 1969: 400 p.

Gorf, W. R., MatsumiYa, Y., Aluson, T. and GoFf, G. D. Cross-modality comparisons of averaged evoked potentials. In E. DoNCHIN and D. B. LindsL.EY (Eds.), Average evoked potentials: methods, results and evahations. NASA SP-191. Washington, D.C., 1969: 95-141.

McCalıum, W, C. and KNott, J. R. (Eds.). Event-related slow potentials of the brain; their relations to behavior. Electroenceph, clin. Neurophysiol., 1973, Suppl. 33:390 p. 